\title{
Immunological aspects of inflammatory bowel disease pathogenesis
}

\author{
Tsvetelina Velikova* \\ Clinical Immunology, University Hospital Lozenetz, Kozyak 1 Str., Sofia 1407, Bulgaria
}

\begin{abstract}
Recent advances have provided substantial insight into the pathogenesis of inflammatory bowel disease (IBD). From immunological point of view, the main pathological axis is dysregulation of the mucous immune system and inappropriate immune response to the composition of normal intestinal flora, food antigens and other exogenous factors. The cells involved in the intestinal homeostasis use various mechanisms to promote immune tolerance, inflammation or epithelial restitution. Current aspects in the pathogenesis of IBD are defects in mucous barriers and antimicrobial peptides associated with increased intestinal permeability, innate and adaptive immune dysregulation. Genomic studies also identified predisposing to IBD loci of genes. This review aims to provide a better understanding of the up-todate immunological aspects in IBD pathogenesis, which is the basis for better diagnostic and therapeutic approaches to these diseases.
\end{abstract}

Chronic Inflammatory Bowel Disease (IBD) predominantly affects young people with higher economic impact. IBD is a chronic recurrent disease throughout the whole life of the patients [1]. According to the Montreal classification (2006), IBD comprises of the following diseases: Crohn's disease, ulcerative colitis, indeterminate colitis, unclassified colitis, microscopic colitis [2]. The incidence of IBD is about $160 / 100,000$ [3] with typical north-south gradient, i.e. the frequency is higher in Northern Europe and North America than in the southern parts of these continents.

In genetically predisposed individuals, the interaction of exogenous (composition of normal intestinal flora, food antigens) and endogenous factors (mucosal barrier function, innate and acquired immunity) can lead to dysregulation of mucosal immune function. The essential microbial flora affects immune processes in the gut at the level of secretion of antimicrobial peptides, regulatory and effector immune cells [4]. Thus, the normal flora influences the maintenance of intestinal immunological homeostasis, while dysbiosis induces altered immune responses and causes intestinal inflammation [5], which is associated with the development of some diseases, such as IBD [4].

The normal bowel contains many immune cells that make up the so-called mucosal immune system, charged with the defense of the organism against antigens penetrated through the digestive system. Oral (mucous) tolerance is responsible for suppressing the immune response to food antigens and normal microbiota in the intestinal lumen [6]. Part of the mechanisms providing oral tolerance are cellular anergy, clonal deletion, induction of various $\mathrm{T}$ regulatory lymphocytes $(\mathrm{CD} 4+$ or $\mathrm{CD} 8+\mathrm{CD} 25 \pm$ FoxP3+, Th3, Tr1, etc.), secretion of suppressing cytokines (TGF $\beta 1$, IL-4, IL-10) and others [7]. Secretory IgA also has a role in maintaining mucosal immunity through limiting the immune response locally [7]. However, besides tolerance, there is a certain level of so-called "physiological inflammation," which prevents the excessive growth of the normal flora or pathogenic microorganisms.

In IBD some of the oral tolerance mechanisms are disturbed leading to uncontrolled inflammation. It is assumed that genetic predisposition is associated with sensitivity of innate immunity to the normal intestinal flora. Initially, acute inflammation occurs through receptor-mediated recognition of microorganisms and/or their products, PAMPs-sensing by the respective receptors: Toll-Like receptors (TLRs), NOD-like receptors (NLRs), cytosolic DNA sensors, mannose-binding lectin, epithelial cells, antigen-presenting cells, myofibroblasts and other cells in the mucosa [8]. Their activation leads to increased production of key cytokines, chemokines, growth factors [9], such as MCP-1, RANTES, IL-8, C3a, C5a, which attract neutrophils into intestinal tissues through the systemic blood flow by interaction between leukocyte receptor $\alpha 4 \beta 7$ (integrin) and the vascular endothelium (i.e., MadCAM 1) [10]. More quantities of IFN $\gamma$, IL-1a, IL-1 $\beta$, TNF $\alpha$, IL- 6 are secreted, causing an increase in the expression of adhesion molecules on endothelial cells within the blood vessels, which leads to introduction of additional neutrophils [9]. Once in the tissues, neutrophils begin phagocytosis and release calprotectin, lactoferrin and other proteins in the lumen of the gastrointestinal tract, which can be measured in stool samples of IBD patients [11]. The picture described corresponds to the acute inflammation, which usually subsides within hours to days while all neutrophils died [12]. Neutrophils, on the one hand, can promote tissue repair [13] and, on the other hand, help maintain inflammation and remodeling the mucosa by their ability to secrete TNFa [12]. Locally active TNF $\alpha$ and IL- $1 \beta$ can pass into the bloodstream and exert their systemic effects - hyperpyrexia, appetite suppression, induction of cachexia [12], C-reactive protein secretion, causing general malaise.

Other cytokines such as IL-6, TGF $\beta 1$ and GM-CSF, also secreted locally at the sites of acute inflammation, contribute to the activation

${ }^{*}$ Correspondence to: Tsvetelina Velikova, Clinical Immunology, University Hospital Lozenetz, Kozyak 1 Str., Sofia 1407, Bulgaria, Tel: 0035-988-330-6049; E-mail: tsvelikova@medfac.mu-sofia.bg

Key words: inflammatory bowel disease, mucosal immune system, Th17 cells, IL17, Treg cells

Received: August 10, 2018; Accepted: August 24, 2018; Published: August 28 , 2018 
and differentiation of antigen-presenting cells and T-lymphocytes [1], which also triggers the acquired immunity. $\mathrm{CD} 4+\mathrm{T}$ cells are activated in the lamina propria where they produce an excessive number of inflammatory cytokines, which in turn induce differentiation of macrophages, B cells, etc, and chronic inflammation occurs. Since macrophages and lymphocytes live days, weeks or even years, chronic inflammation could be of long duration [12]. There are many T-helper cells which promote inflammation in IBD: Th1, secreting IFN $\gamma$ and inducing transmural granulomatous inflammation in Crohn's disease, Th2 cells secreting IL - 4, -5 and -13 which induce the mucocutaneous inflammation in ulcerative colitis and Th17 lymphocytes, secreting mainly IL-17, IL-21, responsible for the attraction of neutrophils to the site of inflammation [14]. However, Th17 cells also participate in physiological functions in the organisms, such as defense against fungi and extracellular bacteria [15]

Mucosal inflammation comprises of these immunological mechanisms, which normally arise in response to an infectious agent and are usually inhibited after a certain time in order to limit the tissue damage. It is believed that dysregulated control can be one of the mechanisms for the transition of acute inflammation into the chronic one [16].

Currently, some authors still describe IBD as disease due to defects in the mucosal barrier and antimicrobial peptides $\beta$-defensins, $\alpha$ - defensins associated with increased intestinal permeability [17]. According to some authors, ulcerative colitis is a disease with impaired mucus production. Reduced antimicrobial activity in the mucous membrane mucosa leads to easier passage of microbial flora into the mucosa which triggers inflammatory responses with the corresponding tissue damages [18]. There is evidence that NOD2 receptor mutation recognition, which recognizes bacteria by the muramyl dipeptide and thus contributes to the maintenance of the mucosal barrier, is associated with the onset of Crohn`s disease [19].

The immunological homeostasis in the mucosa depends on the balance between anti- and proinflammatory cytokines, as well as on induction and maintenance of certain subpopulations of lymphocytes capable of secreting suppressive and/or proinflammatory cytokines [20]. The reciprocal interaction between $\mathrm{T}$ regulatory and Th17 lymphocytes allows for a change in the balance between them in order to restore and promote the oral tolerance or developing autoimmune diseases, such as IBD. The development of therapeutic strategies with monoclonal antibodies against certain cytokines or subunits and receptors important for the differentiation, maintenance or secretion of Th17 cells are promising in patients with such type of immunemediated diseases, as well as for finding clinically useful markers for the diagnosis and follow-up of IBD patients.

Other authors suggest that IBD has infectious etiology, but this has not been proven in the years of study. Various studies questioned the issue that multiple pathogens (Salmonella, Shigella, Campylobacter, Clostridium difficile) can initiate IBD by inducing an inflammatory response which the mucosal immune system is not able to control [10].

Recent studies in the field of intestinal flora have shown that the balance between commensal and pathogenic microflora is not disturbed in IBD but rather the diversity of strains compared to healthy individuals is reduced $[18,20]$. Exposure to microbes during early childhood is associated with the prevention of IBD development [18], which is part of the so-called hygiene theory. This exposure to pathogenic microorganisms is important to occur in certain agesensitive periods when the oral tolerance develops [21].
Psychosomatic factors arise after tough life events, such as divorce, death or illness in the family, severe separation, interpersonal conflicts, or other stressful situations have been implicated in worsening of IBD symptoms.

The effect of smoking is different for IBD entities. The risk of developing ulcerative colitis in smokers is $60 \%$ lower than in nonsmokers-i.e. smoking prevents the development of the disease. On the other hand, ex-smokers have a 1.7-fold higher risk of developing Crohn`s disease compared to people who have never smoked. Smoking leads to a two times higher risk of Crohn`s disease development [11].

IBD are polygenic diseases. At present, about 100 disease-related loci of different chromosomes are described [22]. About one-third of these genetic risk factors are common to both Crohn's disease and ulcerative colitis, which speaks of overlapping immunopathogenesis and accordingly explains the epidemiological observations of the presence of both diseases in the same families and the similarities in response to given therapeutic agents [22]. Genomic studies in IBD have identified gene-susceptible loci of genes associated with diseases [23]. Mutations and polymorphisms have been described in receptors, cytokines, antimicrobial peptides, and others associated with 163 IBD loci [24,25]. However, genetic factors are responsible for part of the pathogenesis of diseases. Interactions between genes and the environment, or so-called epigenetic factors, are responsible for the phenotypic expression of the genetic terrain [26]. IBD associates epigenetic processes such as DNA methylation, histone modification, mRNA interactions, conformational changes in proteins and other [3]. Furthermore, genes associated with IBD can be divided into several groups: related to innate immunity, mucous membrane defects, autophagy, endoplasmic reticulum and metabolic stress; related to the regulation of acquired immunity and related to the development and cessation of the inflammatory process. Moreover, many of the genetic risk factors in IBD are also associated with the risk of developing other immune-mediated diseases: rheumatoid arthritis, psoriasis, ankylosing spondylitis, type 1 diabetes, asthma and systemic lupus erythematosus [22].

\section{Conclusion}

Studies in IBD pathogenesis aim at a better understanding of diseases and elucidation of dysregulated immune processes, thus improving the diagnosing process and therapeutic approaches. The current treatment options for IBD patients are directed to disease control and long-term remission in patients. All of this supports the fact that the drugs currently used in IBD patients suppress immune responses but do not change the pathogenesis of the disease.

\section{References}

1. Longo D, Fauci A, Kasper D, Hauser S, Jameson J, et al. (2008) Harrison's Principles of Internal Medicine. (1 $7^{\text {th }}$ edn), McGraw Hill Education, USA.

2. Satsangi J, Silverberg MS, Vermeire S, Colombel JF (2006) The Montreal classification of inflammatory bowel disease: controversies, consensus, and implications. Gut 55: 749-753. [Crossref]

3. Cooke J, Zhang H, Greger L, Silva AL, Massey D, et al. (2012) Mucosal genome-wide methylation changes in inflammatory bowel disease. Inflamm Bowel Dis 18: 21282137. [Crossref]

4. Chung H, Kasper DL (2010) Microbiota-stimulated immune mechanisms to maintain gut homeostasis. Curr Opin Immunol 22: 455-460. [Crossref]

5. Hisamatsu T, Kanai T, Mikami Y, Yoneno K, Matsuoka K, et al. (2013) Immune aspects of the pathogenesis of inflammatory bowel disease. Pharmacol Ther 137: 283 297. [Crossref]

6. Smith KM, Eaton AD, Finlayson LM, Garside P (2000) Oral tolerance. Am J Respir Crit Care Med 162: S175-178. [Crossref] 
7. Montilla NA, Blas MP, Santalla ML, Villa JMM (2004) Mucosal immune system: A brief review. Immunologia 23: 207-216

8. Otte JM, Rosenberg IM, Podolsky DK (2003) Intestinal myofibroblasts in innate immune responses of the intestine. Gastroenterology 124: 1866-1878. [Crossref]

9. Pang G, Couch L, Batey R, Clancy R, Cripps A (1994) GM-CSF, IL-1 alpha, IL-1 beta, IL-6, IL-8, IL-10, ICAM-1 and VCAM- 1 gene expression and cytokine production in human duodenal fibroblasts stimulated with lipopolysaccharide, IL-1 alpha and TNFalpha. Clin Exp Immunol 96: 437-443. [Crossref]

10. Longo DL, Fauci AS (2010) Harrison - Gastroenterology and Hepatology. Available at: https://www.passeidireto.com/arquivo/19642073/harrison---gastroenterology-andhepatology/31.

11. Mahid SS, Minor KS, Soto RE, Hornung CA, Galandiuk S (2006) Smoking and inflammatory bowel disease: a meta-analysis. Mayo Clin Proc 81: 1462-1471. [Crossref]

12. McDonald T, Bateman ACMD (2006) Immunology and Diseases of the Gut. ( $1^{\text {st }}$ edn), Remedica Publishing, UK.

13. Fournier B, Parkos C (2012) The role of neutrophils during intestinal inflammation. Mucosal Immunol 5: 354-366. [Crossref]

14. Velikova T, Kyurkchiev D, Spassova Z, Karakolev I, Ivanova-Todorova E, et al. (2017) Alterations in cytokine gene expression profile in colon mucosa of Inflammatory Bowel Disease patients on different therapeutic regimens. Cytokine 92: 12-19. [Crossref]

15. Milner JD, Sandler NG, Douek DC (2010) Th17 cells, Job's syndrome and HIV: opportunities for bacterial and fungal infections. Curr Opin HIV AIDS 5: 179-183. [Crossref]
16. Pinchuk IV, Mifflin RC, Saada JI, Powell DW (2010) Intestinal mesenchymal cells. Curr Gastroenterol Rep 12: 310-318. [Crossref]

17. Klag T, Stange EF, Wehkamp J (2013) Defective Antibacterial Barrier in Inflammatory Bowel Disease. Dig Dis 31: 310-316. [Crossref]

18. Nuding S, Antoni L, Stange EF (2013) The host and the flora. Dig Dis 31: 286-292. [Crossref]

19. Couturier-Maillard A, Secher T, Rehman A, Normand S, De Arcangelis A, et al. (2013) NOD2-mediated dysbiosis predisposes mice to transmissible colitis and colorectal cancer. J Clin Invest 123: 700-711. [Crossref]

20. Hand T, Belkaid Y (2010) Microbial control of regulatory and effector T cell responses in the gut. Curr Opin Immunol 22: 63-72. [Crossref]

21. Olszak T, An D, Zeissig S, Vera MP, Richter J, et al. (2012) Microbial exposure during early life has persistent effects on natural killer T cell function. Science 336: 489-493. [Crossref]

22. Khor B, Gardet A, Xavier RJ (2011) Genetics and pathogenesis of inflammatory bowel disease. Nature 474: 307-317. [Crossref]

23. Van Limbergen J, Russell RK, Nimmo ER (2007) Genetics of the innate immune response in inflammatory bowel disease. Inflamm Bowel Dis 13: 338-355.

24. Franchimont D, Louis E (2010) Genetics of inflammatory bowel disease. Bull Mem Acad R Med Belg 165: 435-449. [Crossref]

25. Graham DB, Xavier RJ (2013) From genetics of inflammatory bowel disease to mechanical insights. Trends Immunol 34:371-378. [Crossref]

26. Velikova T, Kyurkchiev D, Ivanova-Todorova E, Spassova Z, Stanilova S, et al. (2016) Cytokines in inflamed mucosa of IBD patients. New Insights Inflamm Bowel Dis: 71-92.

Copyright: (C2018 Velikova T. This is an open-access article distributed under the terms of the Creative Commons Attribution License, which permits unrestricted use, distribution, and reproduction in any medium, provided the original author and source are credited. 